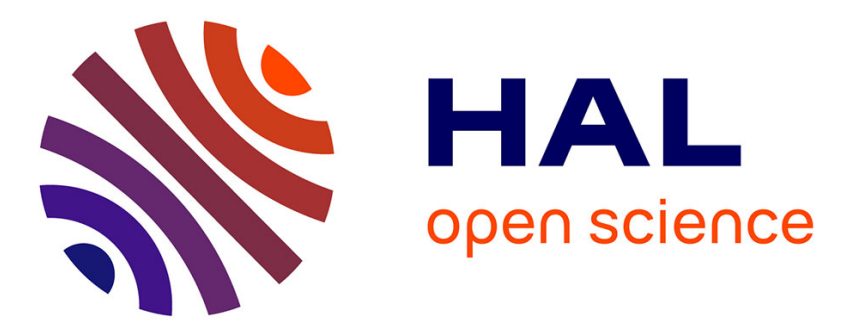

\title{
Role of autobiographical memory in the impact of MBCT on dysfunctional attitudes, depressive symptoms and anxiety in bipolar I patients
}

Aurélie Docteur, Christine Mirabel-Sarron, Héline Kaya Lefèvre, Loretta Sala, Mathilde Husky, Joel Swendsen, Philip Gorwood

\section{- To cite this version:}

Aurélie Docteur, Christine Mirabel-Sarron, Héline Kaya Lefèvre, Loretta Sala, Mathilde Husky, et al. Role of autobiographical memory in the impact of MBCT on dysfunctional attitudes, depressive symptoms and anxiety in bipolar I patients. Journal of Affective Disorders, 2020, 276, pp.907-913. 10.1016/j.jad.2020.07.072 . hal-03091007

\section{HAL Id: hal-03091007 https://hal.science/hal-03091007}

Submitted on 7 Jan 2021

HAL is a multi-disciplinary open access archive for the deposit and dissemination of scientific research documents, whether they are published or not. The documents may come from teaching and research institutions in France or abroad, or from public or private research centers.
L'archive ouverte pluridisciplinaire HAL, est destinée au dépôt et à la diffusion de documents scientifiques de niveau recherche, publiés ou non, émanant des établissements d'enseignement et de recherche français ou étrangers, des laboratoires publics ou privés. 
Research paper

\title{
Role of autobiographical memory in the impact of MBCT on dysfunctional attitudes, depressive symptoms and anxiety in bipolar I patients
}

\author{
Aurélie Docteur ${ }^{\mathrm{a}}$, Christine Mirabel-Sarron ${ }^{\mathrm{a}}$, Héline Kaya Lefèvre ${ }^{\mathrm{a}, \mathrm{e}, *}$, Loretta Sala ${ }^{\mathrm{a}}$, \\ Mathilde Husky $^{\mathrm{b}}$, Joel Swendsen ${ }^{\mathrm{c}}$, Philip Gorwood ${ }^{\mathrm{a}, \mathrm{d}}$ \\ ${ }^{a}$ GHU Paris Psychiatrie et Neurosciences, Hôpital Sainte-Anne, CMME, F-75014 Paris, France \\ ${ }^{\mathrm{b}}$ Laboratoire de Psychologie EA4139, Université de Bordeaux, Bordeaux, France \\ ${ }^{\mathrm{c}}$ INCIA, UMR 5287, CNRS/Université de Bordeaux, Bordeaux, France \\ ${ }^{\mathrm{d}}$ Université de Paris, Institute of Psychiatry and Neuroscience of Paris (IPNP), INSERM U1266, F-75014 Paris, France \\ ${ }^{\mathrm{e}}$ Université de Paris, LPPS, F-92100 Boulogne-Billancourt, France
}

A R T I C L E I N F O

\section{Keywords:}

Bipolar disorder

Mindfulness-based cognitive therapy

Cognitive reactivity

Autobiographical memory

Dysfunctional attitudes

\begin{abstract}
A B S T R A C T
Background: The literature suggests that cognitive reactivity in bipolar patients can increase relapse vulnerability, is enhanced by depressive mood and dysfunctional attitudes, and could be improved with MBCT. Autobiographical memory (AM) could be involved in cognitive reactivity, and improved with MBCT training. This study aims to investigate the effect of MBCT for bipolar patients on depressive and anxious symptoms, dysfunctional attitudes and AM, and the predictive versus mediating role of AM in the impact of MBCT on clinical symptoms.

Methods: Sixty-two outpatients diagnosed with bipolar I disorder were assigned to MBCT and were compared to 37 bipolar patients on a waiting list. Affective symptoms and dysfunctional attitudes were explored using selfreport inventories (BDI, BAI, DAS) and AM was assessed using the Autobiographical Memory Test.

Results: Patients receiving MBCT demonstrated significantly decreased depressive symptoms, dysfunctional attitudes, overgeneral memories and omissions, and increased specific memories. General AM and omissions at baseline respectively predicted lower anxiety and dysfunctional attitudes improvement following therapy, but the improvement of AM did not explain the impact of MBCT on depression and dysfunctional attitudes improvement.

Limits: Further studies should consider patients' therapeutic adherence and mechanisms involved in MBCT in order to better apprehend how MBCT may reduce dysfunctional attitudes and improve AM in bipolar patients. Conclusion: Results are consistent with the hypothesis that MBCT reduces cognitive reactivity and AM impairment in bipolar disorders. Findings suggest that AM training prior to MBCT may influence MBCT efficacy, but that MBCT efficacy on AM and clinical symptoms are non-related phenomena.
\end{abstract}

\section{Introduction}

Bipolar disorder is a severe psychiatric disorder known for its chronicity and high relapse rate. Residual symptoms such as depressive symptoms, anxiety and dysfunctional attitudes and irrational beliefs can be persistent between episodes, increasing relapse vulnerability by enhancing cognitive reactivity (Gruber, 2011; Johnson et al., 2007; Lam et al., 2004; Scott et al., 2000).

The idea behind cognitive reactivity (Sher et al., 2005; Segal, 1988) is that dysfunctional attitudes and irrational beliefs exist in patients with history of depression, and that earlier episodes of depression established an association between those negative beliefs and negative mood state. According to previous studies, dysfunctional attitudes and irrational beliefs are going to be reactivated when mild negative mood state occurs, but only among patients with a history of depression (Gemar et al., 2001; Miranda and Persons, 1988; Miranda et al., 1990). The installation of those patterns will enhance relapse vulnerability overtime. Therefore, dysfunctional attitudes and depressive symptoms from previous episodes contributed to cognitive reactivity, which will likely in returns enhance these very same symptoms.

Thereby it seems crucial to investigate factors that could contributed to cognitive reactivity, for example by enhancing dysfunctional attitudes and beliefs, one of those potential factors being autobiographical memory (AM).

\footnotetext{
* Corresponding author at: GHU Paris Psychiatrie et Neurosciences, Hôpital Sainte-Anne, CMME, F-75014 Paris, France.

E-mail address: h.kaya_lefevre@ghu-paris.fr (H. Kaya Lefèvre).
} 
Literature mostly highlight the role of overgeneral AM in affective disorders, which could be defined by fewer specific memories and greater general memories (Moore and Zoellner, 2007; van Vreeswijk and Jan de Wilde, 2004). In his cognitive theory of depression, Beck (1976) suggested that depressed patients tend to be characterized by overgeneral and negative memories. In fact, recent studies confirmed these hypotheses among depressed patients (Young et al., 2013; Dalgleish et al., 2007; Williams et al., 2007; Dickson and Bates, 2006; MacKinger et al., 2000) and bipolar patients (Bozikas et al., 2019; Young et al., 2016; Kim et al., 2014; Mowlds et al., 2010; Scott et al., 2000), highlighting less specific and more general AM when compared to healthy individuals.

Impaired AM, and more especially overgeneral memories (OGM), appears to be a crucial phenomenon involved in difficulties to regulate emotions (Liu et al., 2014; Raes et al., 2003; Van Daele et al., 2013). It has been shown to be a predictor of the course of depressive symptoms (Brittlebank et al., 1993; Dalgleish et al., 2007; Peeters et al., 2002; Hermans et al., 2008) and a stable marker of vulnerability to depression and bipolar disorder; enhancing vulnerability to both disorders, and impairing recovery between episodes (Nandrino et al., 2002; Williams et al., 2007; Mackinger et al., 2000; Spinhoven et al., 2006; Kim et al., 2014; Dempsey et al., 2014; van Minnen et al., 2005; Gibbs and Rude, 2004; Peeters et al., 2002).

How individuals retrieve personal memories of past experiences can impact their representation of present and future events and the processing of emotional and cognitive material in daily life (Williams, 2006; Raes et al., 2003). Overgeneralizing negative memories and failing to retrieve specific positives ones could contributes to mood disturbance and cognitive distortions by leading to an overgeneral negative perception of oneself (Beck, 1976; Kaya Lefèvre et al., 2019), and therefore be involved in cognitive reactivity by enhancing negative believes.

However, results from the literature on AM in bipolar disorder still are inconsistent (Quinlivan et al., 2017); and, as pointed by Bozikas et al. (2019), additional research is necessary to better apprehend AM in bipolar disorder.

These considerations would indeed be especially relevant among bipolar patients, considering that most of the research in this area has focused on unipolar depressive disorder; although previous studies suggested that dysfunctional attitudes and autobiographical memory could be even more impaired among bipolar patients than among unipolar patients (Perich et al., 2011; Mowlds et al., 2010; Mansell and Lam, 2004). In fact, neural correlates involved in AM differ between bipolar patients and depressed patients (Young et al., 2016); which highlight the necessity to keep investigating AM specificity in bipolar disorder.

Mindfulness-Based Cognitive Therapy (MBCT) (Segal et al., 2002) aims at modifying cognitive and affective processes by developing acceptant and non-judgmental observations, and has initially been shown to prevent depressive relapses (Bondolfi et al., 2010; Godfrin and van Heeringen, 2010; Kuyken et al., 2008; Ma and Teasdale, 2004; Teasdale et al., 2000).

Recent meta-analysis indicates promising results for MBCT on a large range of psychiatric disorders (Strauss et al., 2014; Chiesa and Serretti, 2011), including bipolar disorder (Lovas and SchumanOlivier, 2018). Open trials (Weber et al., 2010; Miklowitz et al., 2009) and randomized controlled trials (Perich et al., 2013a, 2013b; Williams et al., 2008; Kenny and Williams, 2007) have indeed demonstrated the feasibility and the efficacy of MBCT in reducing anxious and depressive symptoms in bipolar patients.

MBCT for bipolar patients has also been shown to have beneficial effects on mood regulation, cognitive functioning such as attentional abilities and frontal-executive control, residual depressive symptoms, mindfulness abilities, and ruminations (Lovas and SchumanOlivier, 2018).

However, the factors involved in MBCT efficacy for bipolar patients has been seldom studied, and, as previously pointed out, autobiographical memory appears to be an interesting characteristic to consider in the improvement of clinical symptomatology.

The literature suggests that MBCT could help decrease overgeneral memories and increase specific autobiographical memory (Kuyken et al., 2010; Williams et al., 2000), by helping patients to switch from an abstract-ruminative thinking style to a more direct moment-to-moment experience. However, these results have been seldom replicated, and exclusively among depressed patients (Williams et al., 2000) or in general population samples (Heeren et al., 2009). To our knowledge, the effect of mindfulness training on autobiographical memory has not been investigated among bipolar patients, despite AM being a crucial cognitive factor that could help explain differential responses rates following MBCT and better comprehend MBCT efficacy on clinical improvement.

This study aims to (1) explore the effect of MBCT for bipolar patients on depressive symptoms, anxiety, dysfunctional attitudes and autobiographical memory, and (2) investigate the predictive and intermediate role of autobiographical memory in the impact of MBCT on clinical improvement.

Given the focus of MBCT in modifying relationships of thoughts, feelings and internal experiences (Cahn \& Polish, 2006) and in line with the literature (Perich et al., 2013a, 2013b; Kuyken et al., 2010; Heeren et al., 2009; Williams et al., 2000), we hypothesized that Mindfulness Based Cognitive training will reduce depressive and anxious symptoms, dysfunctional attitudes and over-generalized autobiographical memory, and improve memory specificity. As AM impairment can be considered a stable marker of bipolar disorder increasing the in-between episodes symptomatology and impacting the course of symptoms, we also expect that AM at baseline predicts clinical improvement following therapy, that AM improvement mediates the impact of MBCT on clinical improvement (depression, anxiety, dysfunctional attitudes), and finally that AM improvement is associated with clinical improvement in others symptoms.

\section{Method}

\subsection{Participants and procedure}

Patients were recruited in a psychiatric university hospital in Paris. Ninety-nine outpatients currently meeting DSM-IV criteria for bipolar I disorder participated in this study. Patients were randomly assigned to MBCT group or waiting list. Sixty-two patients received MBCT plus medication and were assessed at baseline and at post-treatment two months later (MBCT group). Thirty-seven patients receiving medication and on a waiting list were also assessed at baseline and on average 2 months later (control group).

Inclusion criteria were as follows: (a) patient diagnosed with type I bipolar disorder for at least 6 months based on the SCID-1 (First et al., 2002); (b) patients aged 18 to 65 years and (d) patients fluent in written and spoken French.

Exclusion criteria were: (a) patients with current manic, hypomanic, or depressive episode according to the SCID; (b) patients with comorbid psychotic disorder or current substance abuse and/or unstable medical condition; (c) patients without pharmacological treatment.

All participants received a letter of information and gave their written consent to participate, and the study was conducted according to ethics recommendations in the Helsinki declaration (World Medical Association, 2013). The study was approved by the local ethics committee (ClinicalTrials.gov ID: NCT02472483).

\subsection{MBCT program}

MBCT intervention consisted in a standard protocol of 8-week program including 2-hour weekly sessions (Segal et al., 2002), and was led by two trained therapists with at least 3 years of experience with 
Table 1

Sociodemographic and clinical characteristics for the MBCT Group and Control group (waiting list) in patients with bipolar disorder.

\begin{tabular}{|c|c|c|c|c|}
\hline Characteristics & MBCT group $(N=62)$ & Control group $(N=37)$ & $t$ or $\chi^{2}$ & $p$ \\
\hline Age (SD) & $47.73(10.46)$ & $47.16(11.70)$ & -2.26 & .805 \\
\hline$\%$ of women & $63 \%$ & $50 \%$ & 1.62 & .268 \\
\hline Age of onset (SD) & $24.11(10.78)$ & $26.51(10.37)$ & 1.07 & .286 \\
\hline Number of prior depressive episodes (SD) & $12.03(12.16)$ & $12.62(15.79)$ & 0.21 & .846 \\
\hline Number of prior manic episodes (SD) & $7.36(8.61)$ & $7.19(8.17)$ & -0.09 & .925 \\
\hline Depressive relapse rate during the study (\%) & $4,83 \%$ & $5,43 \%$ & & \\
\hline Manic relapse rate during the study (\%) & $0 \%$ & $0 \%$ & & \\
\hline
\end{tabular}

MBCT. Therapy sessions included guided mindfulness practices (i.e., body scan, sitting meditation) and teaching of cognitive-behaviorale skills.

Patients were asked to practice mindfulness meditation at least 30 min per day to develop moment-to-moment awareness, attentional monitoring and acceptance. However, it was not possible to verify the time devoted to mindfulness practice outside therapy sessions.

\subsection{Instruments}

All patients completed a battery of self-report questionnaires and a clinical interview investigating age of onset of bipolar disorder and number of depressive and manic episodes. The French version of the Structured Clinical Interview for DSM-IV Axis I Disorders (SCID-1) was used to confirm the diagnosis of bipolar I disorder (First et al., 2002).

\subsection{Anxiety and depression}

Symptoms of depression and anxiety were assessed using the short version of the Beck Depression Inventory (BDI-13) (Beck et al., 1961) and the Beck Anxiety Inventory (BAI) (Beck and Steer, 1993), respectively.

Both inventories are respectively a 13 and 21 items self-report instrument with a 4-points Likert scale. The BDI investigates depressive symptoms and the severity of depression, and the BAI investigates the intensity of anxiety symptoms experienced during the last 7 days. Both are widely used and have demonstrated good psychometric properties among several samples (Beck et al., 1988; Freeston et al., 1994; Bourque and Beaudette, 1982, 1974). The BDI scores can be categorized as low (0-3), mild depression (4-7), moderate depression (8-15) and severe depression $(\geq 16)$, and the BAI scores can be classified as low anxiety ( 0 to 7 ), mild anxiety ( 8 to 15 ), moderate anxiety (16 to 25 ) and severe anxiety (30 to 63$)$.

\subsection{Dysfunctional attitudes and beliefs}

The Dysfunctional Attitudes Scale (DAS, Weissman, 1978) was administered to assess dysfunctional attitudes and beliefs. The DAS is a self-report instrument designed to investigate the presence and intensity of dysfunctional attitudes, and consists in a 40-item scale. Participants answered on a 7-point Likert scale. Higher scores represent stronger dysfunctional attitudes and beliefs. Psychometric properties were satisfactory in a variety of samples (Cane et al., 1986; Olivier and Baumgart, 1985).

\subsection{Autobiographical memory}

The Autobiographical Memory Test (AMT; Williams and Broadbent, 1986) was used to assess specific and over-generalized autobiographical memory. Participants were asked to produce a specific memory in response to a cue word, within a given time limit (1 min). The cue words vary in emotional valence (positive, negative). Individuals' responses are scored as specific memories (i.e., referring to personal past events that had happened at a particular place and time that had lasted less than a day), non-specific memories (i.e., referring to repeated past events and to past events that lasted longer than a day), and omissions (failures to recall a specific memory within the time limit $-30 \mathrm{~s}$ ).

\subsection{Data analysis}

Statistical analyses were performed using SPSS 21 (IBM SPSS Statistics for Windows, Version 21.0. Armonk, NY: IBM Corp). Descriptive analyses were performed for quantitative data (mean, standard deviation) and qualitative data (percentage). Between-group differences (MBCT group vs. Control group) were examined using variance analysis. Differences between intake and two-month follow-up variables were compared using Student $t$-test, and effect size differences were calculated using Cohen's $d$ (Sawilowsky, 2009; Cohen, 1988). Linear regression analyses were used to investigate the predictive effect of autobiographical memory (general, specific, omissions) at baseline on clinical symptomatology improvement (BDI-13, DAS, BAI), and the relationship between AM improvement and clinical improvement. Path analyses were conducted using PROCESS statistics for SPSS, in order to test for the mediating effect of autobiographical memory improvement in the impact of MBCT on the improvement of others symptoms. Normal distributions of variables were checked using Kolmogorov-Smirnov Test prior to analysis.

\section{Results}

\subsection{Sociodemographic and clinical characteristics}

Sociodemographic and clinical characteristics at baseline are presented in Table 1. The mean age of the MBCT group $(N=62)$ was 47.73 years $(\mathrm{SD}=10.46)$, and $63 \%$ were females. The mean age of the control group $(N=37)$ was $47.16(\mathrm{SD}=11.70)$, and $50 \%$ were females. The MBCT and control groups did not differ according to age, gender, age of onset of bipolar disorder, number of previous depressive episodes or number of previous manic episodes.

For both groups, a moderate affective symptomatology (BDI $>8$ (moderate depression), BAI $>16$ (moderate anxiety)) was observed at baseline (Table 2).

According to SCID evaluation at T2, 4,83\% patients scored as currently depressed at post-treatment (for the MBCT group), and 5,83\% at post-waiting list (for the control group); highlighting depressive relapses that occurred during the study period (considering that they did not scored as currently depressed at baseline) (Table 1). No patient scored as currently manic at $\mathrm{T} 2$, and no other depressive or maniac relapses have been reported by therapist during the study period.

\subsection{Anxiety and depression}

Although no significant within-group changes in depression and anxiety scores was observed (Table 2), the MBCT group improved significantly more than the control group according to depression scores $(p=.024)$, but not according to anxiety scores $(p=.847)$. Differences in depression scores improvement between both groups can be considered small (Table 3). 
Table 2

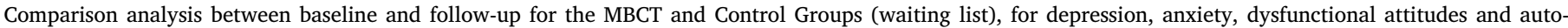
biographical memory in patients with bipolar disorder.

\begin{tabular}{|c|c|c|c|c|c|c|c|c|}
\hline & \multicolumn{4}{|c|}{ MBCT group $(N=62)$} & \multicolumn{4}{|c|}{ Control group $(N=37)$} \\
\hline & Baseline Mean (SD) & Follow-up Mean (SD) & Test t (p) & Cohen's $d$ & Baseline Mean (SD) & Follow-up Mean (SD) & Test $\mathrm{t}(\mathrm{p})$ & Cohen's $d$ \\
\hline BDI-13 (depression) & 9.95 (8.09) & $8.95(7.50)$ & $1.36(0.089)$ & 0.13 & $8.00(5.13)$ & $9.43(6.96)$ & $1.45(0.078)$ & 0.23 \\
\hline BAI (anxiety) & $18.71(12.73)$ & $17.29(12.58)$ & $0.89(0.189)$ & 0.11 & $23.13(15.19)$ & 20.48 (11.09) & $1.20(0.119)$ & 0.20 \\
\hline DAS (dysfunctional attitudes) & $138.58(34.28)$ & $131.04(36.85)$ & $2.17(0.018)$ & 0.21 & $132.76(32.91)$ & $135.54(32.30)$ & $-0.52(0.303)$ & 0.09 \\
\hline AMT & 6.07 & 9.25 (3.59) & -3.46 & 0.90 & 6.04 & 6.78 & -0.95 & 0.17 \\
\hline Specific & $(3.51)$ & & $(0.001)$ & & $(4.12)$ & $(4.37)$ & $(0.177)$ & \\
\hline AMT & 10.75 & $9.07(3.99)$ & 2.09 & 0.43 & 10.91 & 9.74 & 1.27 & 0.28 \\
\hline General & $(3.87)$ & & $(0.022)$ & & $(4.03)$ & $(4.18)$ & $(0.109)$ & \\
\hline AMT & 3.18 & $1.61(1.57)$ & 2.69 & 0.62 & 3.04 & 3.48 & -1.03 & 0.15 \\
\hline Omissions & $(3.21)$ & & $(0.006)$ & & $(2.51)$ & $(3.30)$ & $(0.157)$ & \\
\hline
\end{tabular}

BDI-13: Short version of the Beck Depression Inventory; BAI: Beck Anxiety Inventory; DAS: Dysfunctional Attitudes Scale; AMT: Autobiographical Memory Test.

\subsection{Dysfunctional attitudes and autobiographical memory}

In the MBCT group, DAS scores decreased from baseline to followup $(p=.018)$. In addition, the MBCT group also experienced increases in specific memories $(p=.001)$, and decreases in general memories $(p=.022)$ and omissions $(p=.006)$. Differences between baseline and follow-up can be considered small for dysfunctional attitudes and general memories, medium for omissions, and large for specific memories (Table 2).

No significant differences were observed between baseline and follow-up for these variables in the control group regarding DAS scores, BDI scores, specific memories, overgeneral memories and omissions (Table 2).

When comparing changes in scores between both groups, results showed that the MBCT group improved significantly more than the control group regarding DAS reduction $(p=.048)$, AM omissions reduction $(p=.005)$ and specific AM improvement $(p=.027)$. These differences can be considered small for dysfunctional attitudes, and medium for specific memories and omissions (Table 3).

\subsection{Role of AM in the impact of MBCT on clinical symptoms}

In the MBCT group, more frequent AM omissions at baseline significantly predicted less DAS improvement $(p=.046)$, and higher general AM at baseline significantly predicted less BAI reduction $(p=.036)$. Moreover, $15 \%$ of the variance of the BAI improvement was explained by general memories at baseline, and $14 \%$ of the variance of the DAS improvement was explained by omissions at baseline (Table 4).

In the Waiting List group, general AM at baseline did not predicted BAI reduction $(p=.897)$, and surprisingly, more frequent omissions at baseline were associated with greater DAS improvement overtime ( $p=.038)$; conversely to the MBCT group. In the WL group, $19 \%$ of the variance of DAS improvement was explained by omissions at baseline (Table 4).

No other relationship between the three types of autobiographical
Table 4

Linear regression analysis: predictive effect of $\mathrm{AM}$ at baseline and association between AM improvement and others symptoms improvement.

\begin{tabular}{lllllllll}
\hline DV & IV & $\mathbf{R}^{2}$ & $\beta$ & $\mathbf{B}$ & $\mathbf{p}$ & \multicolumn{2}{c}{ CI 95\% } & \\
\cline { 5 - 7 } & & & & & & & Min & Max \\
\hline MBCT & & & & & & & & \\
BAI evolution & $\begin{array}{l}\text { AMT-general } \\
\text { T1 }\end{array}$ & .15 & .39 & 1.21 & .036 & .09 & 2.34 \\
DAS evolution & $\begin{array}{l}\text { AMT- } \\
\text { omissions T1 }\end{array}$ & .14 & .37 & 2.83 & .046 & .05 & 5.61 \\
WL & & & & & & & \\
DAS evolution & $\begin{array}{l}\text { AMT- } \\
\text { omissions T1 }\end{array}$ & .19 & -0.44 & -6.61 & .038 & -12.81 & -0.41 \\
MBCT + WL & $\begin{array}{l}\text { AMT- } \\
\text { BDI evolution }\end{array}$ & $\begin{array}{l}\text { AMT- } \\
\text { omissions }\end{array}$ & .09 & .29 & .71 & .038 & .04 & 1.38 \\
& evolution & & & & & & & \\
\end{tabular}

$\mathrm{DV}=$ dependant variable; $\mathrm{IV}=$ independant variable; $\mathrm{CI}=$ confidence in terval; $\mathrm{MBCT}=\mathrm{MBCT}$ group $; \mathrm{WL}=$ Waiting List group; $\mathrm{MBCT}+\mathrm{WL}=$ both groups; Evolution $=\mathrm{T} 2$ scores $-\mathrm{T} 1$ scores.

Waiting List group; $\mathrm{MBCT}+\mathrm{WL}=$ both groups; Evolution $=\mathrm{T} 2$ scores $-\mathrm{T} 1$ scores.

BAI: Beck Depression Inventory ; DAS: Dysfunctional Attitudes Scale ; AMT: Autobiographical Memory Test.

memory at baseline and clinical symptomatology improvement was found $(p>.05)$.

A path analysis showed an effect of MBCT (compared to waiting list) on BDI improvement $\left(\mathrm{R}^{2}=0.04, \beta=-0.20, t=-2.05, p=.046\right)$ and omissions reduction $\left(\mathrm{R}^{2}=0.13, \beta=-0.36, t=-2.68, p=.010\right)$, and BDI improvement was significantly predicted by omission reductions $\left(\mathrm{R}^{2}=0.09, \beta=-0.29, t=2.14, p=.038\right)$. However, the bootstrapping indirect effect of MBCT on BDI improvement through omission reduction was not significant (CI 95\% [(-2.97)-(0.07)]).

Results also suggested a role of MBCT on AM specificity improvement $\left(\mathrm{R}^{2}=0.07, \beta=0.27, t=1.972, p=.054\right)$ and DAS improvement

Table 3

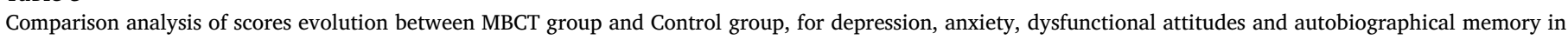
patients with bipolar disorder.

\begin{tabular}{|c|c|c|c|c|}
\hline & MBCT group $(N=62)$ & Control group $(N=37)$ & Test $\mathbf{t}(\mathrm{p})$ & Cohen's d \\
\hline & Mean (SD) & & & \\
\hline BDI-13 improvement (depression) & $-1.00(5.68)$ & $1.43(6.01)$ & $2.00(0.024)$ & .42 \\
\hline BAI improvement (anxiety) & $-2.52(12.59)$ & $-2.03(11.89)$ & $.19(0.424)$ & .04 \\
\hline DAS improvement (dysfunctional attitudes) & $-7.54(24.61)$ & $2.78(32.53)$ & $1.69(0.048)$ & .36 \\
\hline AMT-Specific improvement & $3.18(4.86)$ & $.74(3.74)$ & $-1.97(0.027)$ & .56 \\
\hline AMT-General improvement & $-1.68(4.23)$ & $-1.17(4.44)$ & $.414(0.340)$ & .12 \\
\hline AMT-Omissions improvement & $-1.57(3.08)$ & $.43(2.02)$ & $2.681(0.005)$ & .76 \\
\hline
\end{tabular}

BDI-13: Short version of the Beck Depression Inventory; BAI: Beck Anxiety Inventory; DAS: Dysfunctional Attitudes Scale; AMT: Autobiographical Memory Test. 
$\left(\mathrm{R}^{2}=0.02, \beta=-0.18, t=-1.68, p=.095\right)$, although this was only a trend, but MBCT did not predicted BAI improvement $(p=.650)$ or AM general improvement $(p=.680)$.

None of the three types of AM improvement were associated with DAS improvement nor BAI improvement $(p>.10)$, and AM specificity improvement $(p=.429)$ as well as AM general improvement $(p=.628)$ were not associated with BDI improvement.

Thus, there was no other evidence suggesting that clinical improvement though MBCT was mediated by AM improvement, considering that omissions reduction were the only type of AM improvement associated with clinical improvement (BDI improvement).

\section{Discussion}

The aim of the present study was to examine, on one hand, the effect of MBCT on depressive symptoms, anxiety, dysfunctional attitudes and autobiographical memory in bipolar patients, and on the other, the predictive and intermediate role of AM in the impact of MBCT on clinical symptomatology.

Results indicate a beneficial effect of MBCT on dysfunctional attitudes and irrational beliefs, with an improvement of all three types of autobiographical memory (general, specific, omissions). These results are coherent with the hypothesis that MBCT training can help decrease relapse vulnerability by reducing cognitive reactivity (Heeren et al., 2009; Bishop et al., 2004).

More specifically, differences in effect sizes suggest firstly that MBCT may be more efficient on autobiographical memory than on affective symptoms, and secondly that it may be more efficient in increasing specific memories than in decreasing general memories and omissions.

Previous investigations of depressed patients showed improved specificity in autobiographical memory for persons receiving MBCT (Hargus et al., 2010; Williams et al., 2000) as well as a protective role of this therapy on the deterioration of memory specificity (Hargus et al., 2010). The current findings therefore extend these results by suggesting a similar effect of MBCT in bipolar patients. The finding that MBCT reduced negative thoughts in bipolar patients is also consistent with the objectives of this therapy to target awareness of automatic thoughts which lead to negative ruminations.

Results indicate that greater general $\mathrm{AM}$ and more frequent omissions at baseline are respectively associated with lower improvement of anxiety and dysfunctional attitudes following therapy, which suggest that altered AM could be considered as a cognitive barrier impairing the ability to improve during MBCT. These results might suggest that therapeutic strategies focused on autobiographical memory prior to MBCT may be useful for patients with significantly impaired AM, in order to enhance MBCT efficacy on reducing anxiety and dysfunctional attitudes. Considering dysfunctional attitudes implication in relapse vulnerability, this could help prevent relapse rate following МBCT. However, contrary to our hypothesis, the improvement of autobiographical memory did not mediate the impact of MBCT on clinical symptomatology (depressive symptoms, dysfunctional attitudes). In others words, the efficacy of MBCT on improving autobiographical memory and clinical symptoms may be considered as parallel but nonrelated phenomena, suggesting that both could be supported by shared mechanisms involved in MBCT and/or influenced by common mediators that are yet to be investigated.

The relationship between impaired AM and less clinical improvement would be consistent with previous literature highlighting how personal memories are an important ingredient of mood regulation and psychological functioning (such as problem solving, future planning and self-efficacy) (Addis et al., 2016; Jin et al., 2016; Bandura, 1997; Goddard, Dritschel \& Burton, 1996). We could hypothesize that bipolar patients tend to recall overgeneral negative memories, leading to absolute and negative beliefs ("I am a failure", "no one ever loved me"), and failed to retrieve specific information to balance their mind-set (such as remembering a specific event where they had proof of being loved); which could enhance dysfunctional attitudes and anxiety (Kaya Lefèvre et al., 2019; Addis et al., 2016; Young et al., 2013; Williams et al., 2007; Mathews and MacLeod, 2005; Beck, 1976). It may therefore be interesting to investigate if omissions are more frequent regarding positive memories, and if overgeneralization is more frequent regarding negative memories.

These hypothesis may lead to the idea that encouraging patients to retrieve specific and positive memories (rather than overgeneral and negatives ones) could improve response rate to MBCT.

Surprisingly, in the Waiting List group, more frequent omissions at baseline were associated with less dysfunctional attitudes overtime; conversely to the MBCT group. This could suggest that omissions may be considered as a potential defense mechanism used to prevent the retrieving of negative memories that can enhanced negative beliefs; which could be similar to the "suppression of thoughts" mechanism, although this mechanism is known to increase ruminations on the long run (Purdon, 1999; Wegner et al., 1987; Watkins and Moulds, 2009). However, during MBCT, the very same pattern could have a negative impact by preventing the mechanisms of mindfulness to be fully experience and efficient on negative beliefs.

Results also suggest that omissions (i.e. failing to retrieve autobiographical memory) could be a crucial aspect of AM in the course of clinical improvement: omissions at baseline are associated with less dysfunctional attitudes reduction following therapy, a core mechanism of cognitive reactivity, and omission reduction is associated with depressive symptoms reduction. These findings are particularly interesting, considering that omissions are surprisingly less mentioned in literature than specific and general AM. In fact, previous studies focuses on overgenerality, where "overgeneral" and "specific" AM are often considered as being part of the same dimension. However, omissions are seldom discussed, and are sometimes disregarded or considered as general memories (Moore and Zoellner, 2007; van Vreeswijk and Jan de Wilde, 2004). Our results suggest that, independently of the ability to retrieve specific or general memories, the failing to retrieve autobiographical memories may need to be taken into more consideration. Therefore, furthers studies are needed to investigate the specific role of omissions in affective disorders.

Several limitations should be considered before drawing conclusions from the present findings. While no significant differences were found between the MBCT and control groups at baseline on sociodemographic or clinical variables, patients were not initially matched and intent-to-treat (ITT) was not considered in the analyses of MBCT effects. No follow-up data were available after the study period, which make it impossible to know the depressive and manic relapsing rate overtime following therapy. It is also important to note that the mechanisms of therapeutic change cannot be identified from a large number of potential influences of MBCT, some of which are specific to this form of therapy and others shared across all forms of psychosocial interventions. Future research should consider these issues in examining the mechanisms by which MBCT can be used to reduce dysfunctional beliefs and improve autobiographical memory in bipolar I patients. Furthermore, other characteristics of AM might represent important factors to consider; for example, taking into account the memories' emotional valence, distance in time (eg. childhood, adolescence, adulthood) or proximity (memories about oneself or others) (Maglio et al., 2015), which are known to be involved in psychopathology (Watkins, 2011).

It was also not possible to assess the total time devoted by patients to individual practice in everyday life, although this parameter could have a significant impact on the efficacy of this therapy (Crane et al., 2014; Haley et al., 2014; Perich et al., 2013a).

Finally, it is very difficult to know if the reported changes of dysfunctional attitudes and autobiographical memory are specific for bipolar disorder or are only associated with depressive symptoms. For example, it is very likely that depressive symptoms are more targeted 
by MBCT, AM improvement and dysfunctional attitudes reduction; considering that previous literature on AM and dysfunctional attitudes focuses on depressed mood.

However, this study highlight that AM and dysfunctional attitudes of bipolar patients could be improved with MBCT and that AM could be involved in MBCT efficacy, which is a promising and interesting result considering that both appears more altered in bipolar disorder than among depressed patients (Perich et al., 2011; Mowlds et al., 2010; Mansell and Lam, 2004; Young et al., 2016).

These findings should encourage future research to pursue their investigation of the role of MBCT in reducing cognitive reactivity and improving autobiographical memory in bipolar patients. Long term interventions studies will be needed to investigate if reducing dysfunctional attitudes and improving AM predict in fact lower relapse rates over time among this population.

In conclusion, this study provides novel evidence supporting the role of MBCT in improving cognitive reactivity and autobiographical memory in bipolar I patients. Considering the implication of these mechanisms in relapse vulnerability, the present findings support the indication of MBCT training for bipolar patients.

\section{CRediT authorship contribution statement}

Aurélie Docteur: Conceptualization, Investigation, Methodology, Data curation, Writing - original draft. Christine Mirabel-Sarron: Conceptualization, Investigation, Methodology. Héline Kaya Lefèvre: Formal analysis, Data curation, Writing - original draft, Writing - review \& editing. Loretta Sala: Investigation, Validation, Writing - review \& editing. Mathilde Husky: Formal analysis, Validation, Writing - review \& editing. Joel Swendsen: Validation, Writing - review \& editing. Philip Gorwood: Conceptualization, Supervision, Validation, Writing original draft, Writing - review \& editing.

\section{Declaration of Competing Interest}

Philip Gorwood received during the last 3 years fees for presentations at congresses or participation in scientific boards from AlcediagAlcen, Angelini, GSK, Janssen, Lundbeck, Otsuka, SAGE and Servier. Aurélie Docteur, Christine Mirabel-Sarron, Héline Kaya Lefèvre, Mathilde Husky and Joel Swendsen declare that they have no conflict of interest.

\section{Funding sources}

This research did not receive any specific grant from funding agencies in the public, commercial or not-for-profit sectors.

\section{Supplementary materials}

Supplementary material associated with this article can be found, in the online version, at 10.1016/j.jad.2020.07.072.

\section{References}

Addis, D.R., Hach, S., Tippett, L.J., 2016. Do strategic processes contribute to the specificity of future simulation in depression? Br. J. Clin. Psychol. 55 (2), 167-186. Bandura, A., 1997. Self-efficacy: The Exercise of Control. Freeman, New York. Beck, A., 1976. La Thérapie Cognitive Et Les Troubles Émotionnels. De Boeck, Bruxelles. Beck, A.T., Beamesderfer, A., 1974. Assessment of depression: the depression inventory. Mod Probl Pharmacopsychiatry 7, 151-169.

Beck, A.T., Steer, R.A., 1993. Beck Anxiety Inventory Manual. Psychological Corporation, San Antonio, TX.

Beck, A.T., Ward, C.H., Mendelson, M., Mock, J., Erbaugh, J., 1961. An inventory for measuring depression. Arch. Gen. Psychiatry 4, 561-571.

Beck, A., Steer, R.A., Carbin, M.G., 1988. Psychometric properties of the Beck Depression Inventory: twenty-five years of evaluation. Clin. Psychol. Rev. 8 (1), 77-100.

Bishop, S.R., Lau, M., Shapiro, S., Carlson, L., Anderson, N.D., Carmody, J., Segal, Z.V. Abbey, S., Speca, M., Velting, D., Devins, G., 2004. Mindfulness: a proposed operational definition. Clin. Psychol.: Sci. Pract. 11 (3), 230-241.
Bondolfi, G., Jermann, F., der Linden, M.V., Gex-Fabry, M., Bizzini, L., Rouget, B.W., Myers-Arrazola, L., Gonzalez, C., Segal, Z., Aubry, J.-.M., Bertschy, G., 2010. Depression relapse prophylaxis with mindfulness-based cognitive therapy: replication and extension in the Swiss health care system. J. Affect. Disord. 122 (3), 224-231.

Bourque, P., Beaudette, D., 1982. Étude psychometrique du questionnaire de dépression de Beck auprès d'un échantillon d'étudiants universitaires francophones [Psychometric study of the Beck Depression Inventory on a sample of Frenchspeaking university students]. Can. J. Behav. Sci. 14 (3), 211-218.

Bozikas, V.P., Nazlidou, E.I., Parlapani, E., Alexiadou, A., Skemperi, E., Dandi, E., Bargiota, S.I., Floros, G., Garyfallos, G., 2019. Autobiographical memory deficits in remitted patients with bipolar disorder I: the effect of impaired memory retrieval. Psychiatry Res. 278, 281-288.

Brittlebank, A.D., Scott, J., Williams, J.M.G., Ferrier, I.N., 1993. Autobiographical memory in depression: state or trait marker. Br. J. Psychiatry 162, 118-121.

Cahn, B.R., Polich, J., 2006. Meditation states and traits: EEG, ERP, and neuro- imaging studies. Psychol. Bull. 132, 180-211.

Cane, D.B., Olinger, L.J., Gotlib, I.H., Kuiper, N.A., 1986. Factor structure of the dysfunctional attitude scale in a student population. J. Clin. Psychol. 42 (2), 307-309.

Cohen, J., 1988. Statistical Power Analysis for the Behavioral Sciences, 2nd ed. Lawrence Earlbaum Associates, NJ: Hillsdale.

Chiesa, A., Serretti, A., 2011. Mindfulness based cognitive therapy for psychiatric disorders: a systematic review and meta-analysis. Psychiatry Res. 187, 441-453.

Crane, C., Crane, R.S., Eames, C., Fennell, M.J., Silverton, S., Williams, J.M.G., Barnhofer, T., 2014. The effects of amount of home medication practice in minfulness based cognitive therapy on hazard of relapse to depression in the staying well after depression trial. Behav. Res. Therapy 63, 17-24.

Dalgleish, T., Williams, J.M.G., Golden, A.-M.J., Perkins, N., Barrett, L.F., Barnard, P.J., Yeung, C.A., Murphy, V., Elward, R., Tchanturia, K., Watkins, E., 2007. Reduced specificity of autobiographical memory and depression: the role of executive control. J. Exp. Psychol. Gen. 136 (1), 23-42.

Dempsey, R.C., Gooding, P.A., Jones, S.H., 2014. Assessing the specificity of autobiographical memory in individuals at a trait-based vulnerability to bipolar disorder using a sentence completion task. Memory 22 (3), 222-231.

Dickson, J.M., Bates, G.W., 2006. Autobiographical memories and views of the future: in relation to dysphoria. Int. J. Psychol. 41 (2), 107-116.

First, M.B., Spitzer, R.L., Gibbon, M., Williams, J.B., 2002. Structured Clinical Interview for the DSM-IV Axis I Disorders, clinician version (SCID-CV). Biometrics Research, New York State Psychiatric Institute, New York.

Freeston, M.H., Ladouceur, R., Thibodeau, N., Gagnon, F., Rhéaume, J., 1994. The beck anxiety inventory. Psychometric properties of a French translation. L'Encephale 20 (1), 47-55.

Gemar, M.C., Segal, Z.V., Sagrati, S., Kennedy, S.J., 2001. Mood-induced changes on the Implicit Association Test in recovered depressed patients. J. Abnorm. Psychol. 110 (2), 282-289.

Gibbs, B.R., Rude, S.S., 2004. Overgeneral autobiographical memory as depression vulnerability. Cogn. Ther. Res. 28 (4), 511-526.

Godfrin, K.A., van Heeringen, C., 2010. The effects of mindfulness-based cognitive therapy on recurrence of depressive episodes, mental health and quality of life: a randomized controlled study. Behav. Res. Ther. 48 (8), 738-746.

Goodard, L., Dritschel, B., Burton, A., 1996. Role of autobiographical memory in social problem solving and depression. J. Abnorm. Psychol. 105 (4), 609-616.

Gruber, J., 2011. A review and synthesis of positive emotion and reward disturbance in bipolar disorder. Clin. Psychol. Psychother. 18, 356-365.

Haley, L., Schwartz, D., Bieling, P.J., Irving, J., Corcoran, K., et al., 2014. Mindfulness practice, rumination and clinical outcome in mindfulness-based treatment. Cogn. Ther. Res. 38, 1-9.

Hargus, E., Crane, C., Barnhofer, T., Williams, J.M., 2010. Effects of mindfulness on metaawareness and specificity of describing prodromal symptoms in suicidal depression. Emotion 10, 34-42.

Heeren, A., Van Broeck, N., Philippot, P., 2009. The effects of mindfulness on executive processes and autobiographical memory specificity. Behav. Res. Ther. 47 (5), 403-409.

Hermans, D., Vandromme, H., Debeer, R., Raes, F., Demyttenaere, K., Brunfaut, E., Williams, J.M.G., 2008. Overgeneral autobiographical memory predicts diagnostic status in depression. Behav. Res. Ther. 46, 668-677.

Johnson, S.L., Gruber, J., Eisner, L., 2007. Emotion in bipolar disorder. In: Rottenberg, J., Johnson, S.L. (Eds.), Emotion and Psychopathology: Bridging Affective and Clinical Science. American Psychological Association, pp. 123-150.

Jing, H.G., Madore, K.P., Schacter, D.L., 2016. Worrying about the future: an episodic specificity induction impacts problem solving, reappraisal, and well-being. J. Exp. Psychol.: Gen. 145 (4), 402-418.

Kaya Lefèvre, H., Mirabel-Sarron, C., Docteur, A., Leclerc, V., Laszcz, A., Gorwood, P., Bungener, C., 2019. Time perspective differences between depressed patients and non-depressed participants, and their relationships with depressive and anxiety symptoms. J. Affect. Disord. 246, 320-326.

Kenny, M.A., Williams, J.M.G., 2007. Treatment-resistant depressed patients show a good response to mindfulness-based cognitive therapy. Behav. Res. Ther. 45, 617-625.

Kim, W.J., Ha, R.Y., Sun, J.Y., Ryu, V., Lee, S.J., Ha, K., Cho, H.-.S., 2014. Autobiographical memory and its association with neuropsychological function in bipolar disorder. Compr. Psychiatry 55 (2), 290-297.

Kuyken, W., Byford, S., Taylor, R.S., Watkins, E., Holden, E., White, K., Barrett, B., Byng, R., Evans, A., Mullan, E., Teasdale, J.D., 2008. Mindfulness-based cognitive therapy to prevent relapse in recurrent depression. J. Consult. Clin. Psychol. 76 (6), 966-978.

Kuyken, W., Watkins, E., Holden, E., White, K., Taylor, R.S., Byford, S., Evans, A., Radford, S., Teasdale, J.D., Dalgleish, T., 2010. How does mindfulness-based cognitive therapy work. Behav. Res. Ther. 48 (11), 1105-1112. 
Lam, D., Wright, K., Smith, N., 2004. Dysfunctional assumptions in bipolar disorder. J. Affect. Disord. 79, 193-199.

Liu, X., Liu, Y., Li, L., Hu, Y., Wu, S., Yao, S., 2014. Overgeneral autobiographical memory in patients with chronic pain. Pain Med. 15, 432-439.

Lovas, D.A., Schuman-Olivier, Z., 2018. Mindfulness-based cognitive therapy for bipolar disorder: a systematic review. J. Affect. Disord. 240, 247-261.

Ma, S.H., Teasdale, J.D., 2004. Mindfulness-based cognitive therapy for depression: replication and exploration of differential relapse prevention effects. J. Consult. Clin. Psychol. 72 (1), 31-40.

Mackinger, H.F., Pachinger, M.M., Leibetseder, M.M., Fartacek, R.R., 2000. Autobiographical memories in women remitted from major depression. J. Abnorm. Psychol. 109 (2), 331-334.

Mathews, A., MacLeod, C., 2005. Cognitive vulnerability to emotional disorders. Annu. Rev. Clin. Psychol. 1, 167-195.

Maglio, S.J., Trope, Y., Liberman, N., 2015. From Time Perspective to Psychological Distance (and Back). Éd In: Stolarski, M., Fieulaine, N., van Beek, W. (Eds.), Time Perspective Theory; Review, Research and Application: Essays in Honor of Philip G. Zimbardo. Springer International Publishing, pp. 143-154.

Mansell, W., Lam, D., 2004. A preliminary study of autobiographical memory in remitted bipolar and unipolar depression and the role of imagery in the specificity of memory. Memory 12 (4), 437-446.

Miklowitz, D.J., Alatiq, Y., Goodwin, G.M., Geddes, J.R., Fennel, M.J.V., Dimidjian, S., et al., 2009. A pilot study of mindfulness-based cognitive therapy for bipolar disorder. Int. J. Cogn. Ther. 2, 373-382.

Miranda, J., Persons, J.B., 1988. Dysfunctional attitudes are mood-state dependent. J. Abnorm. Psychol. 97 (1), 76-79.

Miranda, J., Persons, J.B., Byers, C.N., 1990. Endorsement of dysfunctional beliefs depends on current mood state. J. Abnorm. Psychol. 99 (3), 237-241.

Moore, S.A., Zoellner, L.A., 2007. Overgeneral autobiographical memory and traumatic events : an evaluative review. Psychol. Bull. J. 133, 419-437.

Mowlds, W., Shannon, C., McCusker, C.G., Meenagh, C., Robinson, D., Wilson, A., Mulholland, C., 2010. Autobiographical memory specificity, depression, and trauma in bipolar disorder. Br. J. Clin. Psychol. 49 (2), 217-233.

Nandrino, J.L., Pezard, L., Poste, A., Reveillere, C., Beaune, D., 2002. Autobiographical memory in major depression: a comparison between first-episode and reccurent patients. Psychopathology 35, 335-340.

Oliver, J.M., Baumgart, E.P., 1985. The Dysfunctional Attitude Scale: psychometric properties and relation to depression in an unselected adult population. Cognit. Ther. Res. 9 (2), 161-167.

Peeters, F., Wessel, I., Merckelbach, H., Boon-Vermeeren, M., 2002. Autobiographical memory specificity and the course of major depressive disorder. Compr. Psychiatry 43 (5), 344-350.

Perich, T., Manicavasagar, V., Mitchell, P.B., Ball, J.R., 2013a. The association between meditation practice and treatment outcome in Mindfulness-based Cognitive Therapy for bipolar disorder. Behav. Res. Ther. 51 (7), 338-343.

Perich, T., Manicavasagar, V., Mitchell, P.B., Ball, J.R., Hadzi-Pavlovic, D., 2013b. A randomized controlled trial of mindfulness-based cognitive therapy for bipolar disorder. Acta Psychiatr. Scand. 127 (5), 333-343.

Perich, T., Manicavasagar, V., Mitchell, P.B., Ball, J.R., 2011. Mindfulness, response styles and dysfunctional attitudes in bipolar disorder. J. Affect. Disord. 134 (1-3), 126-132.

Purdon, C., 1999. Thought suppression and psychopathology. Behav. Res. Ther. 37, 1029-1054.

Quinlivan, E., Dallacker, M., Renneberg, B., Strasser, E., Fiebig, J., Stamm, T.J., 2017. Autobiographical memory in bipolar disorder and its link to neuropsychological functioning. Psychopathology 50 (4), 246-254.

Raes, F., Herman, D., de Decker, A., Eelen, P., Williams, J.M.G., 2003. Autobiographical memory specificity and affect regulation: an experimental approach. Emotion 3, 201-206.

Sawilowsky, S., 2009. New effect size rules of thumb. J. Mod. Appl. Stat. Methods 8 (2), 597-599.

Scott, J., Stanton, B., Garland, A., Ferrier, I.N., 2000. Cognitive vulnerability in patients with bipolar disorder. Psychol. Med. 30 (2), 467-472.

Segal, Z.V., 1988. Appraisal of the self-schema construct in cognitive models of depression. Psychol. Bull. 103, 147-162.

Segal, Z.V., Williams, J.M.G., Teasdale, J.D., 2002. Mindfulness-based Cognitive Therapy for Depression: A New Approach to Preventing Relapse. Guilford Press, New York.

Sher, C.D., Ingram, R.E., Segal, Z.V., 2005. Cognitive reactivity and vulnerability: empirical evaluation of construct activation and cognitive diatheses in unipolar depression. Clin. Psychol. Rev. 25, 487-510.

Spinhoven, P., Bockting, C.I.H., Schene, A.H., Koeter, M.W.J., Wekking, E.M., Williams, J.M.G., 2006. Autobiographical memory in the euthymic phase of reccurent depression. J. Abnorm. Psychol. 115, 590-600.

Strauss, C., Cavanagh, K., Oliver, A., Pettman, D., 2014. Mindfulness-based interventions for people diagnosed with a current episode of an anxiety or depressive disorder: a meta-analysis of randomised controlled trials. PLoS One 9, 1-13.

Teasdale, J.D., Segal, Z.V., Williams, J.M., Ridgeway, V.A., Soulsby, J.M., Lau, M.A., 2000. Prevention of relapse/recurrence in major depression by mindfulness-based cognitive therapy. J. Consult. Clin. Psychol. 68 (4), 615-623.

Van Daele, T., Van den Bergh, O., Van Audenhove, C., Raes, F., Hermans, D., 2013. Reduce memory specificity predicts the acquisition of problem solving skills in psychoeducation. J. Behav. Ther. Exp Psychiatry 44, 135-140.

van Minnen, A., Wessel, I., Verhaak, C., Smeenk, J., 2005. The relationship between autobiographical memory specificity and depressed mood following a stressful life event: a prospective study. Br. J. Clin. Psychol. 44 (3), 405-415.

van Vreeswijk, M.F., de Wilde, E., 2004. Autobiographical memory specificity, psychopathology, depressed mood, and the use of the Autobiographical Memory Test: a meta analysis. Behav. Res. Ther. 42, 731-743.

Watkins, E., 2011. Dysregulation in level of goal and action identification across psychological disorders. Clin. Psychol. Rev. 31 (2), 260-278.

Watkins, E., Moulds, M., 2009. Thought control strategies, thought suppression and ruminations. Int. J. Cogn. Ther. 2 (3), 235-251.

Weber, G., Jermann, F., Gex-Fabry, M., Nallet, A., Bondolfi, G., Aubry, J.M., 2010. Mindfulness-based cognitive therapy for bipolar disorder: a feasibility trial. Eur. Psychiatry 25, 334-337.

Wegner, D.M., Schneider, D.J., Carter, S.R., White, T.L., 1987. Paradoxical effects of thought suppression. J. Pers. Soc. Psychol. 53, 5-13.

Weissman, M., 1978. Dysfunctional Attitudes Scale. University of Philadelphia, Philadelphia Ph.D. thesis.

Association, World Medical, 2013. World Medical Association declaration of Helsinki. J. Am. Med. Assoc. 310 (20), 2191-2194.

Williams, J.M.G., Barnhofer, T., Crane, C., Hermans, D., Raes, F., Watkins, E., Dalgleish, T., 2007. Autobiographical memory specificity and emotional disorder. Psychol. Bull. 133 (1), 122-148.

Williams, J.M.G., 2006. Capture and rumination, functional avoidance, and executive control (CaRFAX): three processes that underlie overgeneral memory. Cogn. Emotion 20, 548-568.

William, J.M.G., Broadbent, K., 1986. Autobiographical memory in suicide attempters. J. Abnorm. Psychol. 95, 144-149.

Williams, J.M.G., Alatiq, Y., Crane, C., Barnhofer, T., Fennell, M.J.V., Duggan, D.S., et al., 2008. Mindfulness-based cognitive therapy (MBCT) in bipolar disorder: preliminary evaluation of immediate effects on between-episode functioning. J. Affect. Disord. 107, 275-279.

Williams, J.M.G., Segal, Z.V., Teasdale, J.D., Soulsby, J., 2000. Mindfulness-based cognitive therapy reduces overgeneral autobiographical memory in formerly depressed patients. J. Abnorm. Psychol. 109 (1), 150-155.

Young, K.D., Bellgowan, P.S.F., Bodurka, J., Drevets, W.C., 2013. Behavioral and neurophysiological correlates of autobiographical memory deficits in patients with depression and individuals at high risk for depression. JAMA Psychiatry 70 (7), 698-708.

Young, K.D., Bodurka, J., Drevets, W.C., 2016. Differential neural correlates of autobiographical memory recall in bipolar and unipolar depression. Bipolar Disord. 18 (7), 571-582. 